\title{
Italian-Americans and Psychoanalysis
}

\author{
Neil Altman,* Jillian M. Stile**
}

\begin{abstract}
In this paper we address the under-representation of Italian-Americans in psychoanalysis in the United States, both as psychoanalysts and analysands. We suggest that this under-representation has arisen from a confluence of cultural biases in traditional criteria for analyzability and pejorative stereotypes about Italian-Americans that have discouraged their participation to the detriment of the field. The paper suggests that contemporary developments across various schools of psychoanalysis open up new opportunities for rethinking the cultural location of psychoanalysis.
\end{abstract}

Keywords: Psychoanalysis; Italian-Americans; ethnicity; culture.

\section{Introduction}

In recent years there has been some attention paid in the psychoanalytic literature to the lack of diversity in the field, among patients and among analysts in the United States. (Altman, 2010; 2015; 2020 [in press]; Christian \& Gherovici, 2019; Javier \& Herron, 1992; Leary, 1997; 2000; Suchet, 2004; 2007; Tumala-Narra, 2014). When diversity is addressed, the focus is generally on groups referred to as people of color. Little attention has been paid, if any at all, to the under-representation in the field of white people who are not Jewish. Italian-Americans are vastly under-represented in the field as analysts and patients, and almost no attention has been paid in the literature to this skewing of the ethnic and cultural make-up of the field. Italians living in Italy are among the most prominent analysts globally, and psychoanalysis as a field seems to be prospering in Italy. Argentina, with a large population of Italian immigrants and their descendants, has perhaps the most thriving analytic community in the world. Why have Italian-

\footnotetext{
*Ph.D., William Alanson White Institute of Psychiatry, Psychology, and Psychoanalysis. E-mail: altman.neil@gmail.com

**Ph.D., Columbia University Center for Psychoanalytic Training and Research.

E-mail: jstilephd@gmail.com
} 
Americans steered clear of the field, and why has the field steered clear of Italian-Americans?

In this article we will explore the history of Italian immigration to the United States looking for clues as to why and how this situation developed in the United States, to the detriment of all parties, as well as what it shows about our field specifically in the U.S. The historical background for Italian immigration to the United States starts with the unification of Italy in the mid-to late 19th century which resulted in exploitation of the South by the North, in terms of heavy taxation and tariffs on goods produced in the North. The South lacked the minerals needed to support an industrial economy. The South was traditionally agricultural; industry was centered in the North. Most South Italians were farmers, many were illiterate, and were used to living in closeknit villages. The exploitation that followed on the unification of Italy resulted in deepening poverty that motivated people to emigrate, largely to the United States where word had it that opportunity awaited.

What awaited the new immigrants, however, was in some ways as difficult, or more difficult, than what had been left behind. Most immigrants crowded into tenements on the Lower East Side of Manhattan, with multiple families sometimes living in a single apartment. People who were used to a mild climate and much life going on outdoors had to adjust to cold weather for a large part of the year and life without much sunlight where they had to live. With little formal education, Italian immigrants found jobs most available doing manual labor, often back-breaking, in construction work and digging subway tunnels (https://www.loc.gov/teachers/classroommaterials/ presentationsandactivities/presentations/immigration/italian5.html).

Gradually immigrant families saved money and moved out of the tenements of the Lower East Side and into more comfortable quarters of Manhattan and the other boroughs of New York, and into the suburbs. As time went on Italian immigrants started businesses, to the point where by 1960 (Sowell, 2008) the average income of people of Italian origin equaled that of other groups in New York City. By 1934, New York had an ItalianAmerican mayor, Fiorello La Guardia and prominent academics and members of all professions.

Life for Italian immigrants outside of New York also was often challenging. In the South of the United States, Italian-Americans were discriminated against in ways similar to the discrimination against African-Americans. In 1891 a group of 11 Italian-Americans were lynched in New Orleans while being held on suspicion of having killed the police chief and awaiting trial (Jacobson, 1999). In San Francisco there was a significant Italian-American community, while elsewhere in California members of the community were instrumental in starting the wine industry and other areas of agriculture.

There have been two new waves of Italian immigration to the United States since 1945 (Ruberto \& Sciorra, 2017). The first was composed of 
refugees from war-torn and impoverished Italy in the wake of World War II. Between 1946 and 1970, 426,488 Italians immigrated to the United States, joining the descendants of the first wave of immigrants, many millions strong, who by then had become settled in the United States. From 1924 until 1952, Italian immigration had been subject to a quota of 3,845 people per year. In 1952 the quota was raised to 5,666 people per year, but criteria were introduced favoring people based on their skills and education. In 1965, quotas based on national origin were eliminated; in the following 20 years over 200,000 Italians immigrated to the United States. The flow of immigrants began dropping in the 1970s as the Italian economy rebounded from postwar devastation, with advances in many fields including design, food, and entertainment. From that point on, Italian immigrants consisted largely of highly educated and skilled people, seeking opportunity in a globalizing economy. Ruberto and Sciorra (2017) write that this third group of immigrants considered themselves socio-economically and culturally separate from the earlier immigrants and their descendants, "real Italians" as opposed to "Italian-Americans".

Much commentary on Italian immigration to United States focuses on the economic and political progress and assimilation to U.S. culture of the first and second wave of immigrants. Laurino (2015) describes the advancement of Italian-Americans to achievement and prominence in the fields of entertainment and politics, often changing and Anglicizing their names to camouflage their Italian roots and to sidestep prejudicial stereotypes about Italians and Italian-Americans. Laurino describes in detail how stereotypes of Italians as either gangsters and/or as intellectually limited evolved in the context of congressional investigations into organized crime, focusing on Italian-Americans as opposed to the organized crime that existed among other ethnic groups throughout U.S. society. Laurino focuses on the role of the Italian-American Estes Kefauver, a Tennessee congressman who camouflaged his Italian roots by making his Italian name, Estes, his middle name, as the head of commission investigating organized crime. The Kefauver commission, according to Laurino, orchestrated congressional hearings that constructed many of the mafiarelated stereotypes about Italian-Americans that soon came to dominate public attitudes.

Denigrating stereotypes about Italian-Americans persist in the United States, in media portrayals of Italian-Americans that emphasize connections to organized crime, as in the TV series The Sopranos, Francis Ford Coppola's Godfather series and Martin Scorcese's GoodFellas. People from a land with a rich cultural history, the culture that sparked the Renaissance for Europe and the rest of the world, whose cultural contributions persist through the ages since in many fields, these people were reduced to crude stereotypes of uneducated thugs in the new world. 
Conveniently, the third wave of highly educated and skilled immigrants was ignored, often with the collusion of the third wave immigrants themselves who considered themselves an élite among Italian immigrants (Ruberto \& Sciorra, 2017)

Violence was and is glamorized in the films and TV shows even those that portray an evolving Italian-American culture in the United States, like The Sopranos. This show does take note of material progress in the form of big suburban houses like Tony Soprano's, co-existing with a work life marked by naked and heartless violence in the world of men doing business in the street or in strip clubs. Women remain marginal, within the family, sheltered and protected from the violence on which their comfort is presumed to depend, or pole dancing and fucking their patrons in the strip clubs that constitute a kind of office for the men. In these shows, there is a normalization of dissociation between the lives of the women and children, and the work lives of the men. Italian-American life is shown as untouched in any deep way by the Womens' Movement or by the humane sensibilities that are marginalized along with the women and children. Family life and meals together are shown as central to ItalianAmerican life, but in a realm split off from the unfeeling world of men. Tony's wife is smart and savvy, but most of the time seems willfully oblivious to what he does for a living. She has too much at stake. Tony Soprano's daughter is portrayed as smart and aware that something is missing from her exposure to her father's life, capable of being shocked and dismayed when the reality of his brutal life begins to dawn on her. The son, by contrast, is portrayed as mostly clueless. Tony Soprano for all his ostentatious and unfeeling violence, is attached to his mother, but she is portrayed as a caricature of a narcissistic, intrusive and controlling woman. Tony pays homage to her but mostly avoids her. There is a nod to awareness that the men have emotional lives too in the form of Tony Soprano's anxiety disorder and his resort to sessions with Dr. Melfi, an Italian-American female therapist who attempts to bridge the gap of dissociation that inevitably arises when his work life is exposed to his therapist's awareness. In this way, the groundwork is laid by David Chase, the Italian-American creator of the show, for recognition of a psychological level of consciousness interacting with the stereotypical two-dimensional portrayal of Italian-Americans throughout the media.

Caricatures of Italian-American women are on display in the reality TV show, The Real Housewives of New Jersey. These women, like the women in other Real Housewives shows are extremely histrionic. They continually express feelings, but in such an excessive way, with crying and screaming and shouting, that it is difficult to take their emotions seriously. Their lives take shape in a hothouse of rifts, rivalries, and undying resentments. Such depictions are at variance with the history of Italian-American women who 
seriously and thoughtfully challenged their marginalization in the world of work and in U.S. society generally (Guglielmo, 2010).

\section{Italian-Americans in psychoanalysis}

With stereotypes like these circulating in the culture about ItalianAmericans, it is no surprise that one does not generally think of ItalianAmericans and psychoanalysis in the same breath, despite the way in which psychoanalysis thrives in Italy itself. Due to the historical context in which the first and second waves of Italians immigrated to the United States they presented a socio-economic-cultural stereotype that was at odds with the psychoanalytic ideal for patients and analysts getting consolidated in the United States at the time. There was a cultural bias in the ego psychological criteria of analyzability that favored a certain kind of verbal facility, an educational background that favored the development of verbal skills and orientation, and restraint in emotional expression and in behavior. These criteria did not favor a group that, stereotypically, were illiterate, emotionally expressive and warm, and vocationally oriented toward manual labor, i.e. work with the hands. At the same time, these immigrants did not fit the socio-economic ideal of analysts at that time, or at this time for that matter. At the time that the European Jewish analysts were fleeing the Nazis and arriving in New York, private practice in an office with high fees, insulated from the social world, held great appeal. Although Italians were getting settled in the urban economy of the United States at the time, and although many of them were succeeding financially, the stereotype of the poorly paid construction worker or piece worker in the garment district still prevailed. Psychoanalysis, an elite and elitist discipline and practice, culturally favoring the Protestant ethic despite the prevalence of Jews in the field, did not seem to provide fertile soil for Italian transplants.

Contemporary psychoanalysis has evolved in ways that, at least potentially, fits well with a variety of cultural patterns, including those that have evolved among Italian-Americans. A number of developments in psychoanalytic theory have led to an undermining of the polarity between verbalization and action, with verbalization favored. Restraint in action and in emotional expression is no longer taken for granted as a sine qua non for psychoanalytic work. The idea that the analyst must be neutral and anonymous in order to serve as a blank screen for the projection of transference is no longer taken for granted so that the use of the couch and the default silence of the analyst has come into question. There is now more room to view the active expression of feelings toward the analyst as valid material for analytic exploration, aside from restrained expression in words. The cultural biases that underlie the prejudice against manual labor are coming into question. 
After all, work with the hands (manual, literally, with the hands), is always also work with the head and work with the head is not nullified by the active involvement of the hands (cerebral, literally, with the head, can mean disembodied if it not connected with the body, including the hands). The cultural bias against those whose work involves emotions and relationships is illustrated by the fact that people who work with children, mostly women, are vastly underpaid compared to those, mostly men, who move money. With these biases open to question, the biases of psychoanalysis against patients and even analysts who are emotionally expressive, inclined to expression in action (even with their hands) as well as words, is potentially open to interrogation.

The breakthroughs in psychoanalytic theory that opened the field up culturally were initiated by Levenson and Harry Stack Sullivan in the interpersonal school, by Bion and Racker in the Kleinian tradition, and by Mitchell (1988) in the relational tradition. Levenson (1972) postulated that whatever is talked about in a session (on the verbal level) tends to be enacted between patient and analyst (the action level). In Levenson's formulation, words and actions are transforms of each other. Sullivan (1953), the founder of the interpersonal school, referred to the psychiatrist (his word for the analyst, or therapist) as a participant-observer. This simple sounding phrase was actually revolutionary in the context of psychoanalysis, since previously the analyst was thought to be, at least ideally, only an observer, an objective observer. It followed that the analyst was seen as inevitably a participant, even by virtue of his silence, of his efforts not to participate. Participation was no longer an option, it was inherent. In the Kleinian tradition, Bion (1988) saw the analyst as a participant in terms of his or her functioning as a container for the patient's experiences, and Racker (1968) transformed the Kleinian notion of projective identification by demonstrating that the analyst could identify more or less and in various ways with the projections of the patient, thus influencing the fate of projections in the analytic process. In other words, the analyst was in various ways a participant in the process by virtue of his or her countertransference interacting with the patient's transference, the way he or she identified with the psychic content attributed to him or her by the patient, and by virtue of the adequacy of his containing function in helping the patient make psychological meaning of his experiences, especially traumatic experiences.

Greenberg and Mitchell (1983) first pulled together various threads evolving in contemporary psychoanalysis into a relational position, suggested that the interaction between patient and analyst, or between transference and countertransference could give rise to enactments and impasses that could contain the very dynamics that created problems in living for the patient and brought him or her to analysis in the first place. What at first seemed like obstacles to the analytic process could create a unique oppor- 
tunity to work through, in vivo, the relational patterns that were causing problems for the patient in analysis and in life.

From this evolving point of view, patient characteristics that had once seemed to disqualify a person as an analytic patient now could be seen as facilitative of the analytic process, or, more precisely, as potentially either an obstacle or facilitative or both. Schafer (1981) had previewed this point of view by pointing out that for Freud (1920) resistance was both transference and a defense against transference. Schafer was demonstrating that even for Freud, a certain behavior could be itself and a defense against itself. Once defenses against the analytic process could be seen as, in themselves, the analytic process itself, it was no longer possible to think in one dimensional terms about what was a criterion for a good or bad analytic patient. Action, emotional and non-verbal expressiveness, verbal intelligence, all could facilitate and impede the analytic process. Verbal facility can be used for purposes of compliance with the expectations of the analyst, a "false self" participation (Winnicott, 1960/1965) as well as for the purpose of productive psychic exploration. The bottom line here is that culturally-linked qualities such as verbal abilities, tolerance or intolerance for frustration, tolerance or intolerance for anxiety, restraint or spontaneity in action, emotional and nonverbal expressiveness, could all be seen either as potential obstacles or enablers of the analytic process. Additionally, over and over again in the history of psychoanalysis, groups of people who were originally seen as unanalyzable (patients with borderline personality disorder, with narcissistic personality disorder, schizophrenic patients, etc. came to be regarded as analyzable) as new theory and new technical ideas emerged. In any case, there is no longer any reason prima facie to be negatively or positively disposed toward any particular cultural or socio-economic group as members of the analytic community in the role of patients or analysts, though preferences and prejudices persist.

Italian-Americans may be under-represented as psychoanalysts and as patients in connection with a stereotype of this group that does not fit the profile of the ideal analyzable patient. If so, there are a number of problems with this exclusion. First, the stereotype is outdated, based on prejudices that arose in the context of immigration in the late nineteenth and early twentieth centuries, as to who immigrated, why they immigrated, the conditions of life for them in the United States when they first arrived. Second, it was always a stereotype that like all stereotypes, reflected a prejudice and was always a poor fit. Third, even if the stereotype fits in any given case, or in a large number of cases, the characteristics denigrated in the stereotype are not a disqualification for psychoanalysis, either as a patient, or as an analyst, given the new ideas about analyzability, noted just above, that have emerged in contemporary psychoanalytic theory and practice. Yet, the exclusion persists in the United States, as evidenced by the demographics of attendees at psychoanalytic meetings, and the faculty of psychoanalytic institutes. There are, of 
course, notable individual exceptions to the rule, with prominent and strongly contributing Italian-American analysts among the faculty at most if not all institutes as well. Nonetheless, casual disrespectful characterization of Italian-Americans can be heard among analysts from time to time, as if it is taken for granted that no Italian-Americans are within hearing distance.

Here are stereotypes about Italian-Americans that are at variance with commonly held stereotypes about a good analytic patient, along with a refutation of the assumptions behind this dismissiveness. First, that ItalianAmericans are not verbally or intellectually oriented, that they are drawn to manual labor, construction work, trades, music and performance of music, and management of restaurants and food stores. The seed from which this stereotype sprang was that most Italian immigrants after the unification of Italy were from South Italy, where farming was the most common occupation. Living in rural areas, many Southern Italians did not attend school regularly and were, therefore, mostly semi-literate. Urban, industrial society, for which book learning was most useful, lived in the more prosperous North and were less likely to emigrate to escape poverty. The fallacy is that verbal facility and general intelligence are associated primarily with book learning, which is not necessarily the case. Farming and the trades require a great deal of intelligence, information, and problem solving ability, not necessarily acquired from books. In contemporary psychoanalysis, the ability to use relational experiences to grow and change is not necessarily correlated with any particular educational or social class or vocational background.

Purported negative stereotypes about Italian-Americans that are false, overly generalizing, or that expose the negative bias of psychoanalysis as a field are only half the story however. The other half consists of the actual and potential benefit to psychoanalysis from embracing Italian-Americans and what is distinctive about Italian-American culture, allowing our field and our practices to be more enriched by this group of peopele and others with related cultural backgrounds among our patients and practitioners.

Take the emphasis on family. On one hand, group identity seems at odds with the one-to-one psychoanalytic setup and the emphasis on transference to a single person as the royal road of emotional life. For many people that royal road has many lanes, not all of which are heading to the same destination. The psychoanalytic idea that the neurosis can be channeled into the transference neurosis rests on the presumption of the dominance of the mother-child bond in child development. The influence of fathers, siblings, aunts, uncles, other extended family and nannies, is marginal in psychoanalysis and correlates with a general skepticism about how well the classical model relates to real life. For some analysts, the family makes its influential reappearance in the form of the analytic institute, with its various parental surrogates, sibling rivals, and group dynamics. From the margins 
have come questions such as: what about siblings and sibling transference? What about fathers in attachment theory? What about nannies? Is all that extra-psychoanalytic, certainly important but not really psychoanalytic? If so, psychoanalysis is not going to find it easy to be recognized as the purported general psychology. Efforts to integrate psychoanalysis with systems theories, from Bion's early forays into group dynamics and the Tavistock based model of psychoanalytic consultation to groups and organizations, as well as efforts to integrate psychoanalysis with family systems approaches, might have been had a more central place on the agenda if the field had been more open to an emphasis on family.

There is, of course, in Italian-American culture a central place for the mother, the one-to-one relationship, especially in the lives of boys. But then there's the Catholic Church and the Pope, the infallible papa, the centrality of patriarchy. Matriarchy and patriarchy co-exist, complicating any onedimensional theories of emotional development in a multi-dimensional family structure.

Then there's the centrality of food and eating among Italian-Americans. The family life of Italian-Americans often centers on Sunday dinner. People connect over food; aesthetic sensibilities are channeled to a degree into cuisine and cocina. The connection between relatedness and nurturance runs head on into the emphasis on abstinence in the psychoanalytic clinical model. According to the classical criteria of analyzability, if you can't connect around an empty table, or accept that what is on the table are words rather than food, or even dispense with the table altogether, the outlook isn't good for you as an analytic patient. In contemporary psychoanalysis, the centrality of abstinence and anonymity has come into question, making the field more hospitable to those who want to make a place for nurturance. With more openness to Italian-Americans and their culture, we might have gotten farther, sooner, in bringing food to the table.

It seemed fitting that one of our interviews with Italian-Americans in the world of psychoanalysis took place in an Italian restaurant in New York City. This woman generously gave of her time as we ate and talked, with staff of the restaurant gathering around the table to form an intimate, warm and impromptu family as the customers thinned out in the mid-afternoon. Our colleague noted that a tradition of working with the hands, so-called manual labor, had survived transplantation to the United States as her family had built their exurban house from scratch, with their own hands. For her, this sort of work which formed a bridge to life in Southern Italy, coexisted with higher education at a nearby premier colleges for women, where she was introduced to psychoanalysis.

The home culture of Freud and numerous Jewish analysts, is also heavily centered on family and food. Freud (1909), famously, did share meals with some of his patients but he did so outside of sessions, outside of the analytic 
frame, as pointed out by Lipton (1977). This fact leads to a variation on the theme that it is all well and good (to share a meal with your patients) but its not psychoanalysis. Of course, as pointed out by Aron and Starr (2014; 2015) and Gilman (1993), Freud took pains to ensure that his psychoanalysis would fit culturally with the non-Jewish environment of fin de siecle Vienna in which he sought legitimacy. The watch words were scientific objectivity, which ruled out suggestion, influence, and nurturance and ruled in a spartan, intellectual, environment which fit better with a Northern European Protestant ethic than with a Southern European, or Jewish, way of relating around family and food.

Finally, there's the quality of emotional expressiveness among ItalianAmericans that makes for a poor fit with classical analytic anonymity and neutrality. Analysts tend not to talk with their hands or work with their hands, at least while they are on duty. But here again, contemporary psychoanalysis has moved toward viewing all analytic participation as expressive, including silence and other efforts at non-expressiveness. The analytic stance involves exploration of how the patient experiences the analyst's participation, whether that involves overt expressiveness, verbal or non-verbal or extraverbal, or covert expressiveness through silence. Hoffman (1998) once noted shrewdly that transference is the patient's experience of the countertransference. And, as noted earlier, it is a reflection of a general social class bias that we think working with our hands is not also working with our brains, and vice versa; our analytic stance should entail looking at, and reflecting upon, the blind spots that result from this and other biases. If we choose not to engage in psychoanalytic psychotherapy with working class people because they can pay only relatively low fees, let's be up front about that, and not attribute that to a deficit in analyzability. And if we don't recruit members of the working class as people for analytic training, let's acknowledge that many of us are only a generation away from the working class ourselves, and that the cultural differences can make us uncomfortable (Layton, 2006).

\section{Experiences of an Italian-American}

In the course of preparing this article we spoke to a man whose parents had immigrated to the U.S. in the 1920s, before his birth. The father of Mr. $\mathrm{S}$, as we will call him, had worked at first at a grocery store he opened with his sister until she betrayed him by bringing in her husband and icing out Mr. S' father. He went on to open his own fruit stand. He ended up working in the laundry department of a city hospital as a temporary employee for fifteen years, with no retirement benefits nor other perks once that ended. His mother, meanwhile, worked as a contractor crocheting curtain ring covers in the garment industry. Money was short in the family, and Mr. S felt he 
needed to take some responsibility to help his parents make ends meet. By the time he was nine-years-old he felt he had no option but to leave school to work to support his family. He began to skip school, instead selling newspapers on the subway day and night, while also doing other odd jobs for neighbors. In recounting his life as child, Mr. S emphasizes that Italians worked hard to educate their children at any cost, that he left school out of desperation, fully realizing the value of education. He contributed a portion of his earnings to his mother to help with providing food for the family, while assisting her with her work whenever he could.

On a regular basis, usually multiple times a week, Mr. S would meet with his older brothers and a friend in his basement to talk about their lives. He remembers that they supported each other in looking for work, and in navigating the hazards of the streets and the trains. There were real dangers; at one point, Mr. S mentioned that he had to cross Murder Inc. territory alone as a child, to pick up ice cream for the children and for his mother from the shop where his brother worked. He had to be careful not to step on any organized crime toes in the course of his work. The basement group helped each other understand what was going on in their worlds, in their families and on the streets, so that they could feel a measure of control in their lives. Mr. S says: “....to this day, that group therapy and the philosophy we had still exists within me: not getting into trouble, not following the crowd, to associate with people that were meaningful. We were bent on trying to improve ourselves and to take care of ourselves. To this day, going on 87 years old, that lives within me."

Mr. S emphasized that his basement meetings with his brothers and friend were indispensable in his survival of these challenging conditions. What we want to emphasize is that the need to survive in very concrete terms did not preclude the need to process experience in ways that we, as analysts, think of as therapeutic: containing anxiety, formulating experience, providing a holding environment. To the contrary, these children, really, created a therapeutic experience for themselves. In the face of this, how can we professionals question whether they have inner, emotional lives, and a need and desire to process experience verbally and otherwise?

\section{Concluding thoughts}

The emerging focus on diversity in psychoanalysis among patients and psychoanalysis is welcome and needed if psychoanalysis is to find a sustainable place for itself in the larger culture. This development is a sign of the maturity of the field in which we, as analysts, can reflect on our origins and look ahead to how we can develop and expand. In this paper we seek to expand the focus on diversity, noting the relative paucity of Italian Americans 
among patients and analysts, trying to understand the reasons for this underrepresentation, how and why it developed this way, and what we can thereby learn about ourselves and our social position. Most importantly, we can begin to learn about how the field is impoverished by depriving itself of this rich and vibrant community of people, and how the situation might be remedied.

\section{REFERENCES}

Altman, N. (2010). The Analyst in the Inner City: Race, Class, and Culture through a Psychoanalytic Lens. Second Edition. New York and London: Routledge.

Altman, N. (2015). Psychoanalysis in Times of Accelerating Cultural Change: Spiritual Globalization. New York and London: Routledge.

Altman, N. (2020). White Privilege: A Psychoanalytic Perspective. New York and London: Routledge. [In press].

Aron, L. \& Starr, K. (2014). A Psychotherapy for the People: Toward a Progressive Psychoanalysis. London and New York: Routledge.

Aron, L, \& Starr, K. (2015). The ego and the (y)id revisited: commentary on Daniel Gaztambide's "A preferential option for the repressed: psychoanalysis through the eyes of liberation theology". Psychoanalytic Dialogues: The International Journal of Relational Perspectives, 25(6) 714-718.

Bion, W. (1988). Attacks on linking. In: (E. Bott-Spillius, ed.) Melanie Klein Today. Volume 1. 87-101.

Christian, C. \& Gherovici, P. (Eds.) (2019). Psychoanalysis in the Barrios: Race, Class, and the Unconscious. London and New York: Routledge.

Greenberg, J. \& Mitchell, S.A. (1983). Object Relations in Psychoanalytic Theory. Cambridge, MA: Harvard University Press.

Freud, S. (1909). Notes upon a case of obsessional neurosis. Standard Edition of the Complete Psychological Works of Sigmund Freud, Volume X 1909) Two Case Histories (Little Hans and the Rat Man). London: Hogarth Press; pp 151-318.

Freud, S. (1920). A general introduction to psychoanalysis. New York, NY, US: Horace Liveright.

Gilman, S. (1993). Freud, Race, and Gender. Princeton, NJ: Princeton University Press.

Guglielmo, J. (2010). Living the Revolution: Italian Womens' Resistance and Radicalism in New York City 1880-1945. Chapel Hill, N.C: University of North Carolina Press.

Hoffman, I. (1998). Ritual and Spontaneity in Psychoanalysis: A Dialectical Constructivist View. Hillsdale, N.J.: The Analytic Press.

Javier, R. \& Herron, W. (1992). Psychoanalysis, the Hispanic poor, and the disadvantaged: application and conceptualization. Journal of the American Academy of Psychoanalysis, 23, 455-476.

Jacobson, M. (1999). Whiteness of a Different Color: European Immigrants and the Alchemy of Race. Cambridge, MA: Harvard University Press.

Laurino, M. (2015). The Italian-Americans: A History. New York and London: Norton.

Layton, L. (2006). Racial identities, racial enactments, and normative unconscious processes. Psychoanalytic Quarterly, LXXV (1), 237-269.

Leary, K. (1997). Race, self-disclosure, and "forbidden talk": race and ethnicity in contemporary clinical practice. Psychoanalytic Quarterly, 66, 163-189.

Leary, K. (2000). Racial enactments in dynamic treatment. Psychoanalytic Dialogues 10, 639654.

Levenson, E. (1972). The Fallacy of Understanding. New York: Basic Books 
Lipton, S.D. (1977). The advantages of Freud's technique as shown in his analysis of the Rat Man. International Journal of Psychoanalysis, 58, 255-273.

Mitchell, S.A. (1988). Relational Concepts in Psychoanalysis: An Integration. Cambridge, MA: Harvard University Press.

Racker, H. (1968). Transference and Countertransference. New York: Internatinal Universities Press.

Ruberto, L. E. \& Sciorra, J. (Eds.) (2017). New Italian Migrations to the United States. Vol. 1 Politics and History Since 1945. Introduction. Urbana, Ill.: University of Illinois Press.

Schafer, R. (1981). A New Language for Psychoanalysis. New Haven: Yale University Press.

Sowell, T. (2008). Ethnic America: A History. New York: Basic Books.

Suchet, M. (2004). A relational encounter with race. Psychoanalytic Dialogues: the International Journal of Relational Perspectives, 14, 423-438.

Suchet, M. (2007). Unravelling Whiteness. Psychoanalytic Dialogues: The International Journal of Relational Perspectives, 17(6), 867-886.

Sullivan, H.S. (1953). The Interpersonal Theory of Psychiatry. New York: Norton.

Tumala-Narra, P. (2014). Cultural identity in the context of trauma and immigration from a psychoanalytic perspective. Psychoanalytic Psychology, 31(3), 396-409

Winnicott, D. W. (1960/1965). Ego distortion in terms of true and false self. In: The Maturational Processes and the Facilitating Environment. New York: International Universities Press.

Conflict of interest: the authors declare no potential conflict of interests.

Ethics approval and consent to participate: the manuscript does not contain any elements that would allow the recognition of the patient.

Received for publication: 3 March 2020.

Accepted for publication: 24 April 2020.

${ }^{\circ}$ Copyright: the Author(s), 2020

Licensee PAGEPress, Italy

Ricerca Psicoanalitica 2020; XXXI:251

doi:10.4081/rp.2020.251

This article is distributed under the terms of the Creative Commons Attribution Noncommercial License (by-nc 4.0) which permits any noncommercial use, distribution, and reproduction in any medium, provided the original author(s) and source are credited. 
